\title{
DFT studies of the conversion of four mesylate esters during reaction with ammonia
}

\author{
Andrzej Nowacki • Karol Sikora • \\ Barbara Dmochowska • Andrzej Wiśniewski
}

Received: 1 January 2013 / Accepted: 20 March 2013 / Published online: 10 April 2013

(C) The Author(s) 2013. This article is published with open access at Springerlink.com

\begin{abstract}
The energetics of the Menshutkin-like reaction between four mesylate derivatives and ammonia have been computed using B3LYP functional with the $6-31+\mathrm{G}^{* *}$ basis set. Additionally, MPW $1 \mathrm{~K} / 6-31+\mathrm{G}^{* *}$ level calculations were carried out to estimate activation barrier heights in the gas phase. Solvent effect corrections were computed using PCM/B3LYP/6-31+G** level. The conversion of the reactant complexes into ion pairs is accompanied by a strong energy decrease in the gas phase and in all solvents. The ion pairs are stabilized with two strong hydrogen bonds in the gas phase. The bifurcation at $\mathrm{C} 2$ causes a significant activation barrier increase. Also, bifurcation at C5 leads to noticeable barrier height differentiation. Both B3LYP/6-31+G** and MPW1K/6-31+G** activation barriers suggest the reaction 2 $\left(2 \mathrm{a}+\mathrm{NH}_{3}\right)$ to be the fastest in the gas phase. The reaction 4 is the slowest one in all environments.
\end{abstract}

Keywords Ammonium salts · DFT calculations ·

Menshutkin-like reaction · Nucleophilic substitution · THF conformation

\section{Introduction}

Menshutkin was the first scientist to describe the reaction leading to the formation of quaternary ammonium salts (QASs) [1]. In Menshutkin's classical method (the Menshutkin reaction, MR) an alkyl halide (an electrophile) is treated with a tertiary, heterocyclic amine (acting as a nucleophile). The MR has been used to obtain QASs from different classes of organic compounds. Twenty years after

\footnotetext{
A. Nowacki $(\bowtie) \cdot$ K. Sikora $\cdot$ B. Dmochowska $\cdot$ A. Wiśniewski Faculty of Chemistry, University of Gdańsk, Sobieskiego 18, 80-952 Gdańsk, Poland

e-mail: anowacki@chem.univ.gda.pl
}

Menshutkin's original work, Fisher and Raske proved its usefulness for the synthesis of $N$-glycopyranosyl quaternary salts [2].

Detailed studies of the MR have answered the questions regarding both the mechanistic aspects of this reaction and the experimental conditions required for it to occur. Now we have a profound understanding of the factors influencing this reaction: the solvent, the nucleophile and the leaving group. It has been established that polar solvents stabilize both the transition state and the ionic products, thereby speeding up the reaction. In contrast to polar solvents, the MR is dramatically retarded in less polar media.

The alkyl halide can be replaced by a sulfonate ester, which leads to a reaction analogous to the classical MR. This kind of reaction has been used to synthesize $\mathrm{N}$ glycoammonium and $N$-glycopyridinium tosylates [3-7].

The classical MR has been the subject of extensive theoretical study [8-20]; at first, the reaction between ammonia and methyl halide was mostly explored in this way. Such a simple model enables calculations to be performed in both the gas phase and in solution. Recently, however, thanks to the increase in computational efficiency, a significantly extended model has been used for the calculations [19].

Our group has long been interested in the synthesis of quaternary aminium salts [3-6] via the halide and sulfonate ester derivatives of monosugars and alditols. In recent years we have been concentrating on the theoretical aspects of the reaction between sulfonate esters and tertiary amines, both aliphatic and heterocyclic [21-23]. In continuation of our theoretical studies, we now present the results concerning the ammoniaassisted conversion of four mesylate derivatives. Surprisingly, no theoretical studies of the reaction between ammonia and sulfonate esters have yet been carried out, in contrast to the classical MR. The structures studied and the IUPAC names of the three mesylates 
are shown in Fig. 1. The salts under discussion are analogues of $(+)$-muscarine, the principal alkaloid in some poisonous fungi. There has been a resurgence of interest in muscarine in recent years following the discovery of a relationship between a cholinergic deficit and the pathology of Alzheimer's disease [24]. We also did the calculations for the conversion of methyl mesylate. Our aim was to produce a kinetic and thermodynamic description of this type of modified MR. As before, we also wanted to assess the influence of the branching three bonds distant from the reaction center (the methyl or methoxy group bound to C5 of the THF ring is cis-oriented in relation to $\mathrm{C} 1$ ). With this work we have completed the review of different nucleophilic agents typically used in the classic variant of the MR.

\section{Computational details}

All the calculated structures were prepared in the MOLDEN program [25]. The geometries were then optimized using density functional theory (DFT) based on Becke's three-parameter hybrid exchange functional [26] involving the gradient-corrected correlation functional of Lee, Yang and Parr [27], with the splitvalence basis set including polarized and diffuse functions $[28,29]-\left(B 3 L Y P / 6-31+G^{* *}\right.$ method $)$. Optimizations for reactant complexes and transition states were additionally done using the MPW1K/6-31+ $\mathrm{G}^{* *}$ method [30]. This functional (Pedrew-Wang 1-parameter model for kinetics, MPW1K) gives remarkably accurate activation barrier heights. The optimization was considered satisfactory if the energy difference between optimization cycles was less than $1 \times 10^{-6}$ Hartree and a gradient of $<1 \times 10^{-4}$ a.u. was achieved. The convergence of all the systems studied was checked by harmonic vibrational analysis. No imaginary frequencies were observed for the ground state and there was only one for the transition state.

Solvent effects were included in the calculations employing the self-consistent reaction field SCRFPCM solvation model [31] for the reactions studied in chloroform $(\in=4.9)$ and water $(\in=78.39)$ at the B3LYP/6-31+G** level. Implicit solvent calculations imply the generation of a vacuum cavity inside a continuous and homogeneous dielectric field. In PCM model the cavity is built up by a series of interlocking atomic spheres. We used UA0 with scale factor alpha $=1.2$ for water and 1.4 for chloroform [18]. Individual spheres were centered on acidic hydrogen atoms.

All DFT calculations were done with the aid of the Gaussian 03 program [32].

\section{Results and discussion}

General characteristic of the reaction pathway

The studied reactions together with atom numbering order are shown in Scheme 1. The atom numbering order presented in Scheme 1 is not compatible with the names shown in Fig. 1 and IUPAC recommendations, but we use it in order to make the presentation of our results clearer.

Reaction $\mathbf{1}$ is closely related to the classical MR, differing only in the leaving group. We carried out calculations for this reaction to compare the influence of leaving group exchange on the reaction.

The next two reactions ( $\mathbf{2}$ and $\mathbf{3}$ ) involve anhydroalditols, whereas the last one (4) relates to the glycoside. The spatial arrangement of the aglycone (here, the $\mathrm{OCH}_{3}$ group) in relation to the THF ring in glycosides is governed by the steric factor and by the so-called exo-anomeric effect. This effect forces the aglycone to be located in a position where an acute torsion angle is formed in relation to the endocyclic oxygen atom. This requirement is satisfied in two orientations: $-s c$ and $+s c$ (Fig. 2), but the steric hindrance present in the $+s c$ conformation disqualifies it, so the preferred one is $-s c$.

The $\mathrm{H}_{3} \mathrm{C}-\mathrm{O} 5-\mathrm{C} 5-\mathrm{O} 2$ torsion angle ranges from $-65^{\circ}$ to $-82^{\circ}$ all along the reaction pathway (Table 1). However, this is not a golden rule, since we showed previously that in the reaction of mesylate derivative $\mathbf{4 a}$ with a bulky trimethylamine the $-s c$ orientation of the methoxyl group appeared to be unfavorable because of steric hindrance and thus changed to ap [21].

The steps of the reactions under discussion are analogous to those reported previously [21-23]. The energy $\left(E_{0}\right)$ and pseudochemical potential $\left(U_{0}\right)$ [33] profiles for the conversion of the mesylates into the corresponding ammonium salts (Fig. 3) in the gas phase and in solvents consists of an asymmetric double-well potential with five stationary points, corresponding to the separated reactants (R), reactant complex (RC), transition state (TS), product complex (PC) and separated ionic products (P). Two reactants (electrophile - mesylate derivative, and nucleophile - ammonia) approach one another, forming a van der Waals reactant complex. This complex converts into an ionic pair, which requires an activation barrier to be overcome. Finally, the constituents of the ionic pair are separated to an infinitely great distance. The main difference between the energy diagrams shown in Fig.3 and those presented elsewhere [21-23] is on the product side. Previously, the last stage of the reaction was endergonic in the gas phase and in chloroform, whereas it was exergonic in polar solvents. In the reactions being studied here, separation of the ion pair constituents requires the application energy in the gas phase and in all solvents. 
Fig. 1 Structures of mesylate derivatives converted into ammonium salts

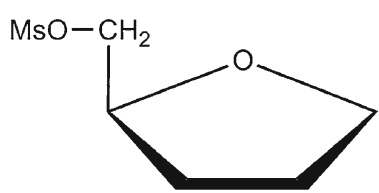

(S)-1,4-anhydro-2,3-dideoxy-5-O-mesylpentitol (2a)

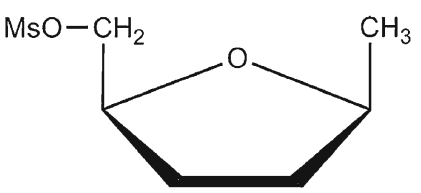

$(2 S, 5 S)$-2,5-anhydro-1,3,4-trideoxy$-6-O$-mesylhexitol (3a)

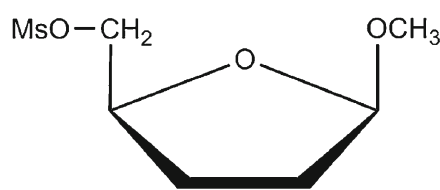

methyl 2,3-dideoxy-5-O-mesyl$-\beta$-D-pentofuranoside (4a)

\section{Gas-phase calculations}

Table 1 lists the activation and reaction energies for both the gas state and solutions, together with important geometrical parameters of all the stationary points on PES. A scaling factor of 0.9877 was used for the zeropoint vibrational energy (ZPVE) correction of the calculated total energies [34].

To discuss the conformational details of the THF ring, the Altona-Sundaralingam (AS) pseudorotational phase angle $(P)$ and the AS puckering amplitude $\left(\phi_{\mathrm{m}}\right)$ were considered $[35,36]$. The THF ring conformations, $P$ and $\phi_{\mathrm{m}}$ values are given in Table 2 together with the set of the endocyclic torsion angles $\phi_{0}-\phi_{4}$, whereas the definition of these angles is shown in Fig. 4. The conformational descriptors that we adopted differ from the classical ones because of the different atom numbering scheme. Table 2 also lists two torsion angles $(\chi)$ describing the spatial disposition of the exocyclic groups.

The calculated geometries together with selected bond distances, valence angles and relative energies corresponding to all the stationary points along the reaction pathway are presented in Figs. 5 and 6. The relative energies refer to the sum of the separate reactant energies.

The first point on the energy curves (Fig. 3) corresponds to the separate reactants, i.e., mesylate derivative and ammonia. In the case of reaction 2 (Table 2) the THF ring takes the $E_{4}$ conformation, $\left(P=349^{\circ}, \phi_{\mathrm{m}}=36^{\circ}\right)$, in which $\mathrm{C} 1$ atom is in the pseudo-equatorial position $\left(\chi_{1}=-144.5^{\circ}\right)$. The same ring conformation is found for the individual mesylate in reaction $4,\left(P=336^{\circ}, \phi_{\mathrm{m}}=36^{\circ}\right)$, whereas the ${ }^{4} E$ conformation is observed for the separate
Scheme 1 Reactions of ammonium salt formation
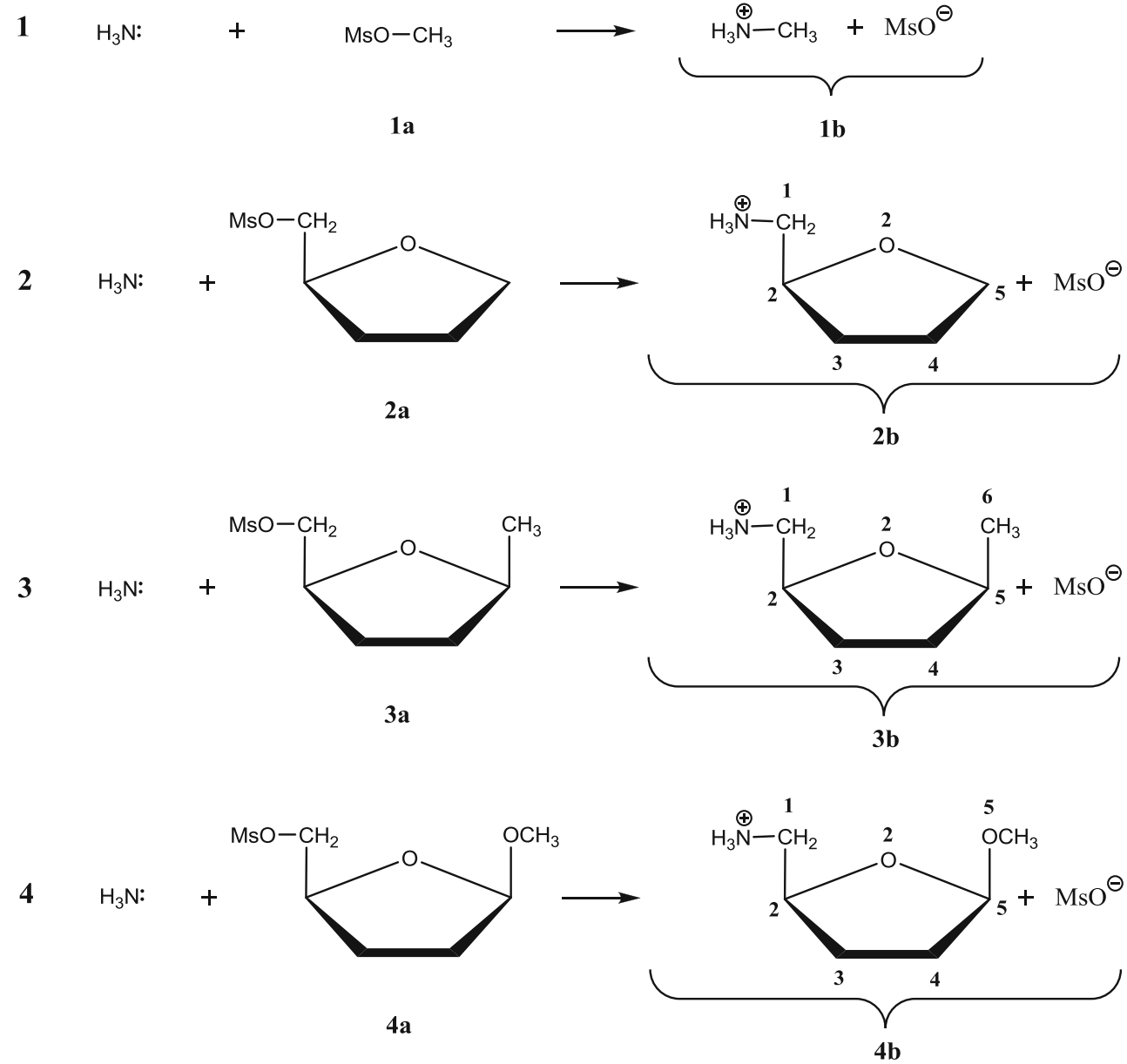


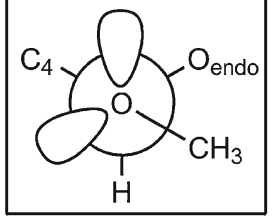

$-S C$

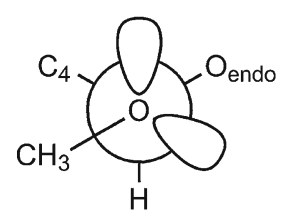

$a p$

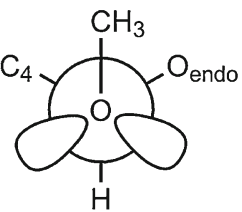

$+s c$
Fig. 2 Rotamers exhibiting possible spatial arrangements of the $\mathrm{OCH}_{3}$ group in relation to the heterocyclic oxygen atom. The preferred orientation is in the box

mesylate in reaction $3\left(P=155^{\circ}, \phi_{\mathrm{m}}=-36^{\circ}\right)$. The $E_{4}$ conformation is free of 1,3-diaxial-like steric interactions and the eclipsed orientation of the substituents, as we described previously [23]. The mesylate $\mathrm{C} 1$ atom in reaction $\mathbf{4}$ is in the pseudo-equatorial orientation $\left(\chi_{1}=-138.5^{\circ}\right)$ whereas the $\mathrm{OCH}_{3}$ group is in the pseudo-axial position $\left(\chi_{2}=84.6^{\circ}\right)$. Thus the THF ring avoids the unfavorable 1,3-diaxial-like steric interactions between these two groups. The THF ring in reaction 3 bears two bulky substituents on the same side of the ring; hence, two reverse conformations should be considered, namely, those in which the $\mathrm{C} 1$ or $\mathrm{C} 6$ atom is in the pseudo-equatorial orientation (the ${ }^{3} E$ or ${ }^{4} E$ conformation respectively). Both conformations have features thought to stabilize five-membered rings because they hold two bulky groups moved away from one another, avoiding steric repulsion, and there are no eclipse orientations of any substituents in the THF ring. According to the B3LYP functional ${ }^{4} E$ conformation, that with the pseudo-equatorially located $\mathrm{CH}_{3}$ group $\left(\chi_{2}=156.7^{\circ}\right)$ and pseudo-axially oriented $\mathrm{CH}_{2} \mathrm{OMs}$ group $\left(\chi_{1}=-100.7^{\circ}\right)$ is more stable by about $1 \mathrm{kcal} \mathrm{mol}^{-1}$.

The next point on the energy diagrams represents the reactant complex. In all the cases studied, the approach of the individual reactants is accompanied by a slight energy decrease (Table 1, Figs. 5 and 6) in the gas phase. Gibbs free energies, however, predict that reactant complex formation will be unfavorable $\left(\Delta G=5.0-6.2 \mathrm{kcal} \mathrm{mol}^{-1}\right)$.

The small value of the complexation energy, $\left(-2.9 \mathrm{kcal} \mathrm{mol}^{-1},-2.2 \mathrm{kcal} \mathrm{mol}^{-1},-2.1 \mathrm{kcal} \mathrm{mol}^{-1}\right.$ and $-2.4 \mathrm{kcal} \mathrm{mol}^{-1}$ for $\mathbf{1 a}, \mathbf{2 a}, \mathbf{3 a}$ and $4 \mathbf{a}$ respectively) indicates that the interaction (hydrogen bond) between these two molecules in this complex is relatively weak. The intermolecular interaction between mesylate and ammonia in reactant complexes is slightly stronger than the one for trimethylamine [21], and comparable with that for pyridine [22, 23]. This may be related to the type of intermolecular interaction. A typical S- $\mathrm{O} \cdots \mathrm{H}-\mathrm{N}$ hydrogen bond stabilizes the reactant complex in these reactions, whereas an atypical $\mathrm{S}-\mathrm{O} \cdots \mathrm{H}-\mathrm{C}$ hydrogen bond interaction was observed for the reactions with trimethylamine [21]. After decades of the controversy on whether $\mathrm{O} \cdots \mathrm{H}-\mathrm{C}$ hydrogen bonds really exist, it is accepted now that they do exist, although $\mathrm{O} \cdots \mathrm{H}-\mathrm{C}$ hydrogen bonds are mostly weak in comparison with classical ones [37].

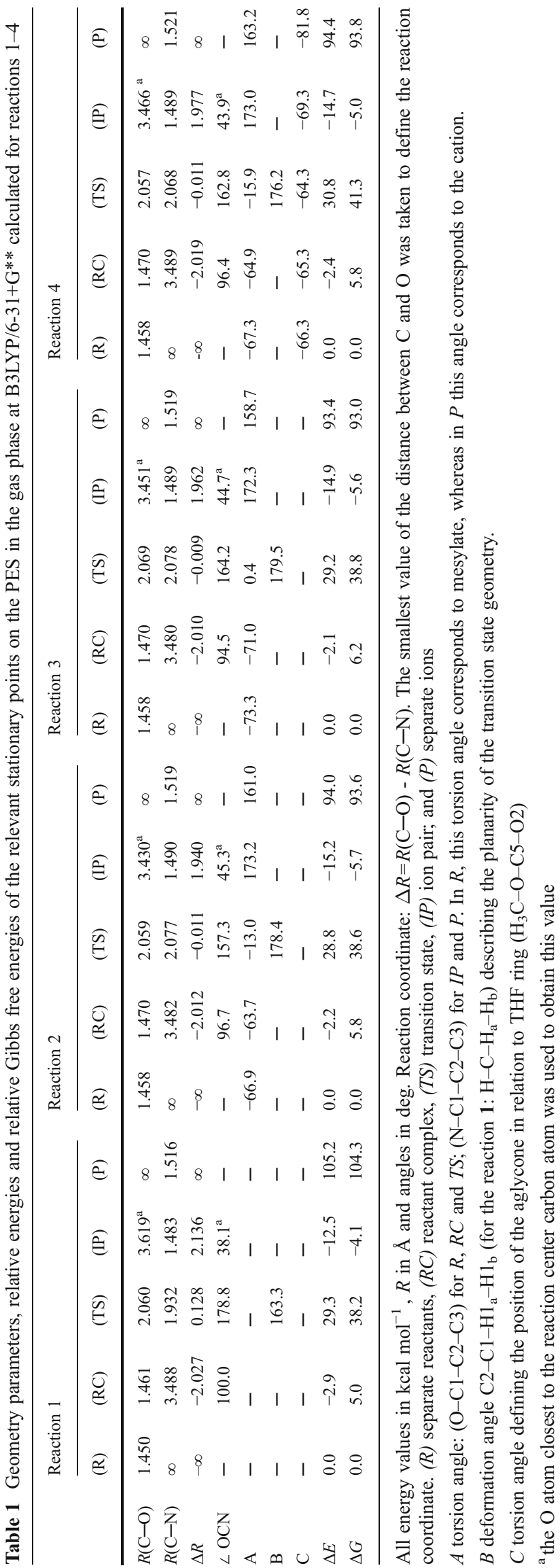




\section{Reaction 1}

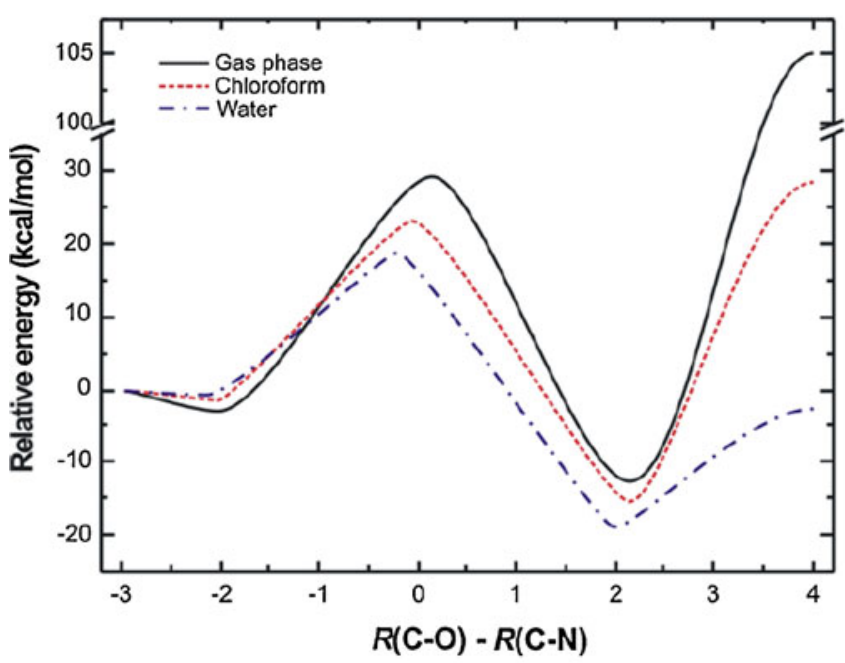

Reaction 3

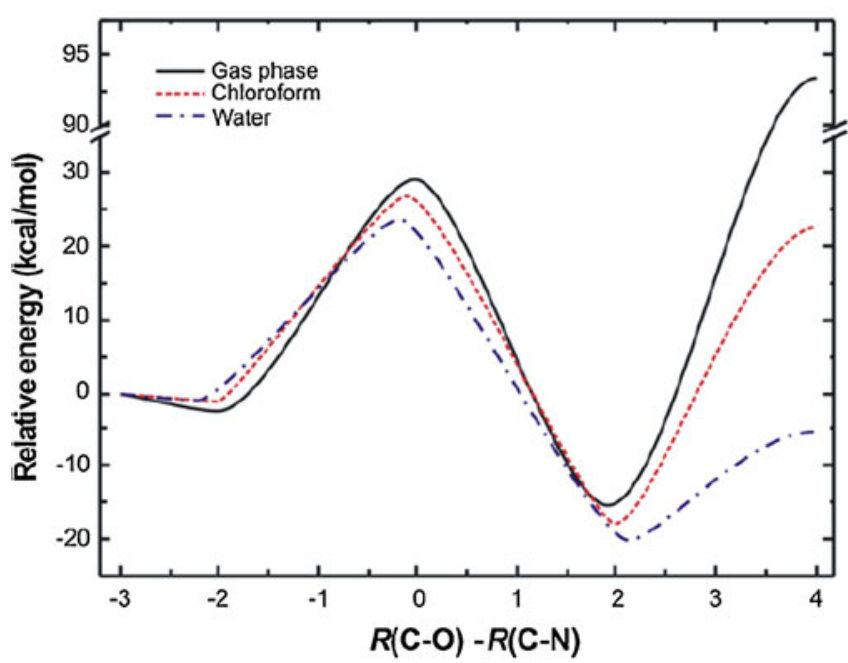

Reaction 2

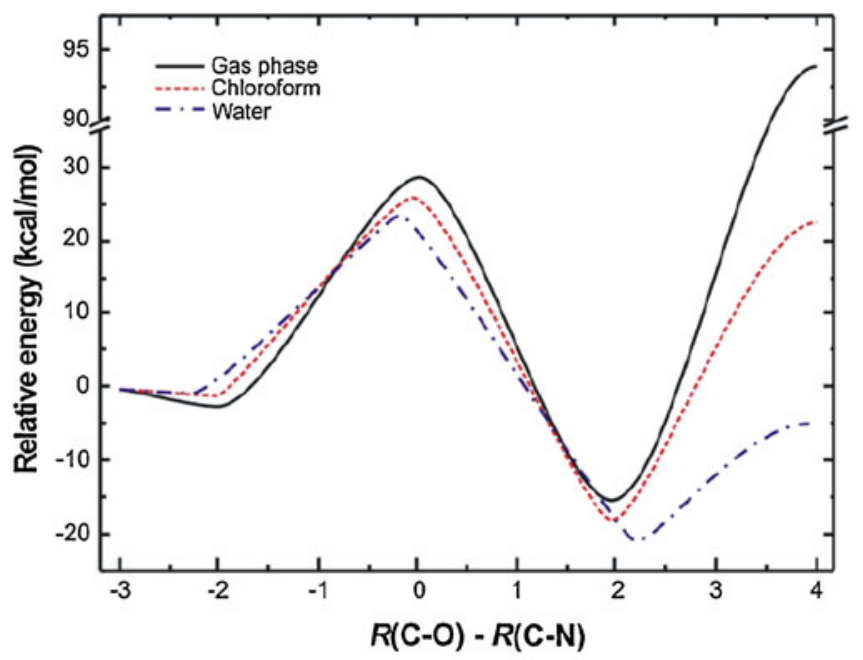

Reaction 4

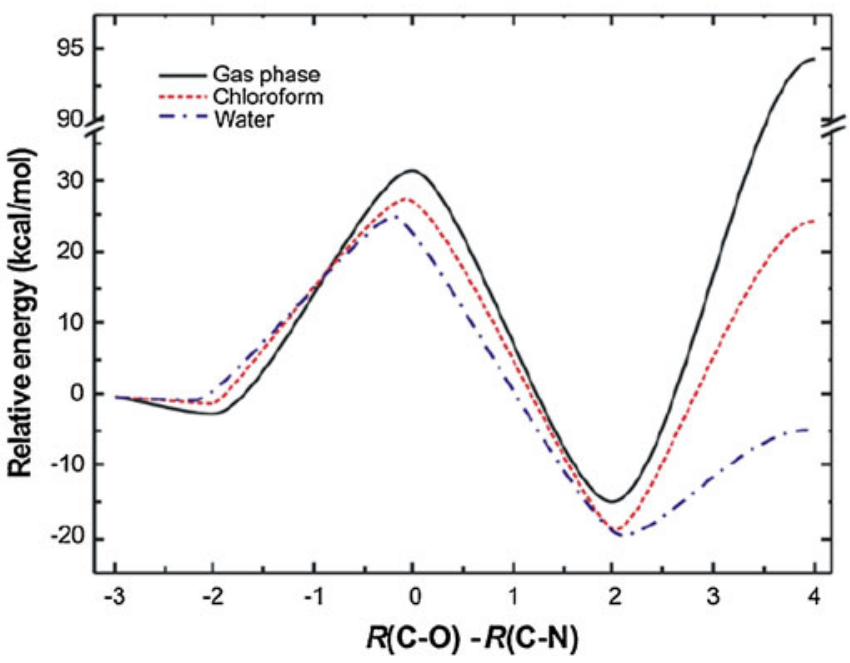

Fig. 3 Energy $\left(E_{0}\right)$ and pseudochemical potential $\left(U_{0}\right)$ profiles for reactions $\mathbf{1 - 4}$ calculated at B3LYP/6-31+G** level in the gas phase, chloroform and water

The shape of the THF ring does not change while reactants are approaching one another. The $E_{4}$ conformation is observed for THF ring in reactant complexes 2a and $\mathbf{4 a}$, whereas the ${ }^{4} E$ conformation is noted in $\mathbf{3 a}$ (Table 2). A noteworthy fact is that in reaction $\mathbf{4}$, two different conformations ( $E_{4}$ for the separate mesylate and ${ }^{2} E$ for the reactant complex) were preferred for the THF ring when the conversion with pyridine was being studied and described [23].

The next stationary point on the energy curve, shown in Fig. 3, corresponds to the transition state. The relative energy values matching the transition states with respect to the separated reactants are given in Table 1 and in Figs. 5 and 6 , whereas the activation barriers relating to the reactant complexes are listed in Table 3.

The geometry of the relevant transition state can be characterized by the $\mathrm{C} \cdots \mathrm{O}$ and $\mathrm{C} \cdots \mathrm{N}$ distances, $\mathrm{OCN}$ valence angles and two torsion angles (A, B, Table 1). Whereas the $\mathrm{C}^{\cdots} \mathrm{O}$ and $\mathrm{C} \cdots \mathrm{N}$ distances are roughly the same in all TSs (about $2.06 \AA$ and $2.08 \AA$ respectively), the $\mathrm{C}^{\cdots} \mathrm{N}$ distance in reaction $\mathbf{1}$ is much shorter $(1.93 \AA)$.

Table 1 and Fig. 5 indicate that the transition state for reaction 1 is linear, the valence angle $\mathrm{O}^{\cdots} \mathrm{C} \cdots \mathrm{N}$ being $178.8^{\circ}$. The other three TSs are slightly bent, the cited valence angle ranging from $\sim 156^{\circ}$ to $\sim 164^{\circ}$, which is the result of the steric hindrance.

The approach of the ammonia molecule to $\mathrm{C} 1$ induces a change in the $\mathrm{O}-\mathrm{C} 1-\mathrm{C} 2-\mathrm{C} 3$ torsion angle (Table 1). In the reactant complex this angle is about $-65^{\circ}$, whereas in the transition state it takes values of $-13.0^{\circ}, 0.4^{\circ}$ and $-15.9^{\circ}$ for reactions 2, 3 and 4 respectively. The observed differences in values of the torsion angle come from the variation of the THF ring conformation. The preferred conformation of the THF ring in the transition state corresponding to conversions 2 
Table 2 Selected torsion angles and calculated values of the pseudorotational phase angle $(P)$ and of the puckering amplitude $\left(\phi_{\mathrm{m}}\right)$ of the THF ring for all stationary points for conversions $2-4$

${ }^{\mathrm{a} D e f i n i t i o n}$ of the torsion angles: $\phi_{0}-\mathrm{C} 5-\mathrm{C} 4-\mathrm{C} 3-\mathrm{C} 2 ; \phi_{1}-\mathrm{C} 4-$ $\mathrm{C} 3-\mathrm{C} 2-\mathrm{O} 2 ; \phi_{2}-\mathrm{C} 3-\mathrm{C} 2-\mathrm{O} 2-$ $\mathrm{C} 5 ; \phi_{3}-\mathrm{C} 2-\mathrm{O} 2-\mathrm{C} 5-\mathrm{C} 4 ; \phi_{4}-$ $\mathrm{O} 2-\mathrm{C} 5-\mathrm{C} 4-\mathrm{C} 3 ; \chi_{1}-\mathrm{C} 1-\mathrm{C} 2-$ $\mathrm{C} 3-\mathrm{C} 4 ; \chi_{2}-\mathrm{R}-\mathrm{C} 5-\mathrm{C} 4-\mathrm{C} 3$, where $\mathrm{R}$ represents the substituent attached to $\mathrm{C} 5$

\begin{tabular}{|c|c|c|c|c|c|c|c|c|c|c|}
\hline & & $P$ & $\phi_{\mathrm{m}}$ & $\phi_{0}$ & $\phi_{1}$ & $\phi_{2}$ & $\phi_{3}$ & $\phi_{4}$ & $\chi_{1}$ & $\chi_{2}$ \\
\hline \multicolumn{11}{|c|}{ Reaction 2} \\
\hline $\mathrm{R}$ & $E_{4}$ & 349 & 36 & 35.6 & -26.0 & 5.2 & 18.2 & -33.6 & -144.5 & - \\
\hline $\mathrm{RC}$ & $E_{4}$ & 345 & 36 & 35.2 & -24.1 & 2.3 & 20.8 & -34.9 & -142.6 & - \\
\hline $\mathrm{TS}$ & ${ }^{3} T_{4}$ & 2 & 39 & 39.1 & -33.4 & 14.3 & 11.0 & -31.6 & -154.5 & - \\
\hline IP & ${ }^{3} T_{4}$ & 4 & 36 & 36.2 & -31.9 & 14.6 & 9.1 & -28.7 & -150.6 & - \\
\hline $\mathrm{P}$ & ${ }^{3} T_{4}$ & 2 & 36 & 36.5 & -31.1 & 13.4 & 10.4 & -29.5 & -148.1 & - \\
\hline \multicolumn{11}{|c|}{ Reaction 3} \\
\hline $\mathrm{R}$ & ${ }^{4} E$ & 155 & -36 & -33.0 & 18.6 & 4.4 & -25.8 & 36.3 & -98.5 & 156.2 \\
\hline $\mathrm{RC}$ & ${ }^{4} E$ & 151 & -37 & -32.0 & 16.5 & 7.0 & -27.8 & 36.8 & -100.7 & 156.7 \\
\hline TS & ${ }^{4} T_{3}$ & 174 & -37 & -37.1 & 28.5 & -8.4 & -15.4 & 32.7 & -92.3 & 153.0 \\
\hline IP & $E_{5}$ & 117 & -39 & -17.7 & -5.0 & 27.9 & -39.4 & 34.5 & -123.2 & 154.0 \\
\hline $\mathrm{P}$ & ${ }^{4} E$ & 149 & -37 & -31.3 & 14.8 & 8.5 & -28.5 & 36.5 & -101.5 & 156.1 \\
\hline \multicolumn{11}{|c|}{ Reaction 4} \\
\hline $\mathrm{R}$ & $E_{4}$ & 336 & 36 & 32.8 & -19.3 & -3.1 & 24.7 & -35.7 & -138.3 & 84.6 \\
\hline $\mathrm{RC}$ & $E_{4}$ & 337 & 36 & 33.0 & -19.8 & -2.5 & 24.2 & -35.5 & -138.9 & 84.8 \\
\hline TS & ${ }^{3} T_{4}$ & 358 & 40 & 39.7 & -31.8 & 11.3 & 14.3 & -33.9 & -154.0 & 86.0 \\
\hline IP & $E_{4}$ & 342 & 36 & 34.5 & -22.3 & 0.5 & 22.0 & -35.2 & -142.1 & 84.9 \\
\hline $\mathrm{P}$ & $E_{4}$ & 334 & 37 & 33.4 & -18.3 & -4.7 & 26.1 & -36.8 & -136.4 & 82.0 \\
\hline
\end{tabular}

and 4 is ${ }^{3} T_{4}\left(P=2^{\circ}, \phi_{\mathrm{m}}=39^{\circ}\right.$ and $P=358^{\circ}, \phi_{\mathrm{m}}=40^{\circ}$ for 2 and 4 respectively, Table 2). This conformation is free of the eclipsed orientation of the substituents and 1,3-diaxial-like steric interactions (in reaction 4) as $\mathrm{C} 1$ is moved away from the THF ring $\left(\chi_{1}=-154^{\circ}\right.$, Table 2$)$. In consequence, the $\mathrm{MsO}$ leaving group is also located beside the THF ring. In reaction 3 the THF ring adopts the ${ }^{4} T_{3}$ conformation $\left(P=174^{\circ}\right.$, $\left.\phi_{\mathrm{m}}=-37^{\circ}\right)$, in which the C6 atom is moved away from the ring $\left(\chi_{2}=153^{\circ}\right.$, Table 2$)$. In this conformation the $\mathrm{MsO}$ leaving group is located above the THF ring.

The $\mathrm{C} 2-\mathrm{C} 1-\mathrm{H} 1_{\mathrm{a}}-\mathrm{H} 1_{\mathrm{b}}$ deformation torsion angle $(\mathbf{B}$, Table 1$)$ reflects the planar placing of substituents at the $\mathrm{C} 1$ atom in the transition state. This indicates that the transition state geometry is exactly halfway between the reactant and product complex for reactions 2, 3 and 4, whereas the late transition state is observed for reaction $\mathbf{1}$.

The calculated barriers are higher than those for the reactions with trimethylamine [21] and pyridine [22, 23], which corresponds to the lower basicity of ammonia in a vacuum (Fig. 7). The proton affinity of ammonia is $204.0 \mathrm{kcal} \mathrm{mol}^{-1}$, but is $225.1 \mathrm{kcal} \mathrm{mol}^{-1}$ and $220.8 \mathrm{kcal} \mathrm{mol}^{-1}$ for trimethylamine and pyridine respectively [38]. The energy barrier is the lowest for reaction 2 but the highest for reaction 4. Interestingly, the energy barrier for reaction $\mathbf{1}$ is higher than for reactions $\mathbf{2}$ and $\mathbf{3}$ according to both B3LYP and MPW1K methods. This stands in contrast to the reactions of the same mesylate derivatives with other nucleophiles studied earlier [21-23], where the barrier was the lowest for the reaction of methyl mesylate with the corresponding nucleophile (Fig. 7). Presumably, hydrogen bond formation between the endocyclic oxygen atom and the hydrogen atom attached to the nitrogen atom stabilizes the transition state geometry. Such an interaction cannot occur in reaction $\mathbf{1}$.

The second minimum on the reaction pathway corresponds to ion pairs. Both $\Delta E$ and $\Delta G$ predict that the conversion of the reactant complexes to the respective ion pairs is accompanied by an energy decrease in the gas phase. This effect is smallest in reaction $\mathbf{1}$ and the energy of the ion pair $1 \mathbf{b}$ is ca $10 \mathrm{kcal} \mathrm{mol}^{-1}$ lower than that of the reactant complex. Interestingly, $\Delta E$ and $\Delta G$ at this stage were expected to be unfavorable for the reaction of methyl mesylate and pyridine [22]. On the other hand, ion pair formation was slightly favorable $\left(\Delta E=-1.5 \mathrm{kcal} \mathrm{mol}^{-1}\right)$ when trimethylamine was the nucleophile [21]. The conversion of complexes into ion pairs is rather more favorable for the remaining three reactions (about $12 \mathrm{kcal} \mathrm{mol}^{-1}$ ) than for reaction $\mathbf{1}$. The constituents of ion pair $\mathbf{1 b}$ are oriented in such a way that the whole geometry has the $C_{s}$ symmetry (Fig. 8), with two carbons, oxygen, sulfur and nitrogen being planar. The anion and the cation are held together due to two strong hydrogen bonds, which may be

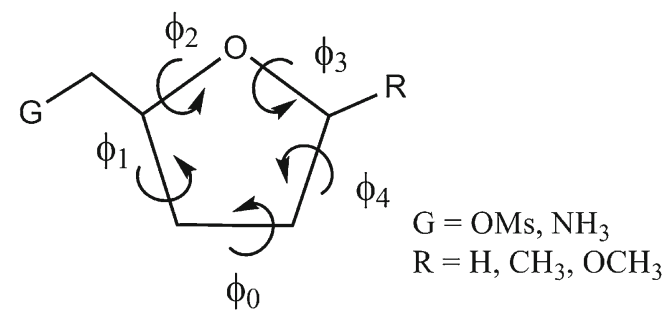

Fig. 4 Definition of the endocyclic torsion angles $\phi_{0}-\phi_{4}$ 


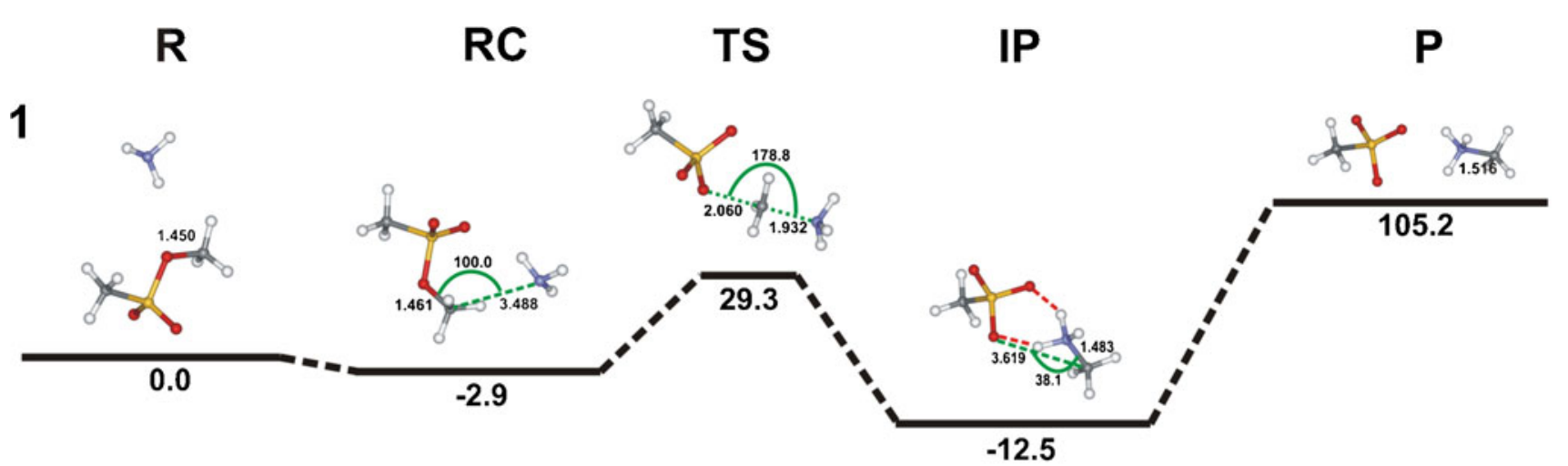

\section{2}

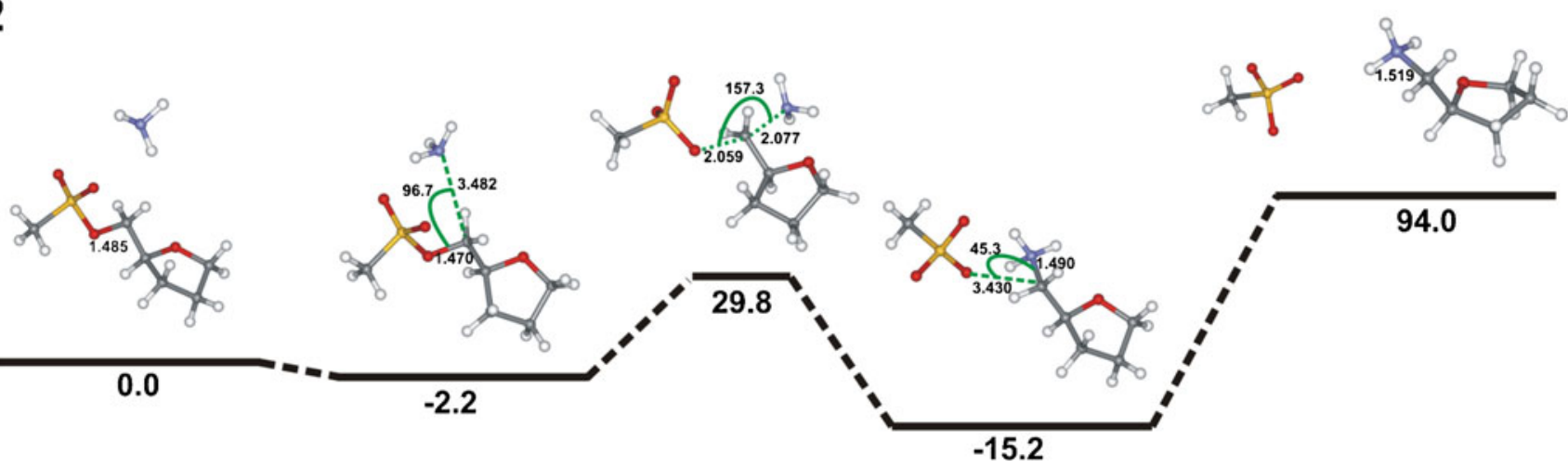

Fig. 5 Geometries of the stationary points and $\Delta E\left(\mathrm{kcal} \mathrm{mol}^{-1}\right)$ computed at the B3LYP/6-31+G** level for reactions $\mathbf{1}$ and 2 in the gas phase. Selected distances in $\AA$, and valence angles in degrees

responsible for the stronger stability of the ion pair. Such interactions are also found in the ion pairs formed in the other reactions studied.

In ion pair $\mathbf{2 b}$ the THF ring has the ${ }^{3} T_{4}$ conformation, $\left(P=4^{\circ}, \phi_{\mathrm{m}}=36^{\circ}\right)$, as in the corresponding transition state, whereas in ion pair $\mathbf{3 b}$ the almost ideal $E_{5}$ conformation of the THF ring $\left(P=117^{\circ}, \phi_{\mathrm{m}}=-39^{\circ}\right)$ is preferred (Table 2). This means that a conformational change occurs on going downhill from the energy maximum to the valley. In the case of reaction 4 the THF ring adopts the same conformation as in the reactant complex, i.e., $E_{4},\left(P=342^{\circ}, \phi_{\mathrm{m}}=36^{\circ}\right)$.

The last stage of the reactions studied consists in the separation of the ion pair constituents. Again, this process is extremely unfavorable in the gas phase. More than $90 \mathrm{kcal} \mathrm{mol}^{-1}$ in relation to the sum of the energies of the individual reactants must be supplied to move the ions to an infinite distance from one another (Table 1). Ion pair dissociation is more endoenergetic here than it was in the reactions with trimethylamine and pyridine [21-23].

\section{Calculations in solution (SCRF-PCM)}

Tomasi's polarizable continuum model (PCM) was used to investigate the influence of the liquid phase on the course of the reactions under scrutiny [31]. The PCM model permits the self-consistent computation of free energies of solvation, including polarized solute/solvent interactions and nonelectrostatic terms in the Hamiltonian. On the other hand it should be emphasized that reaction field models are incapable of modeling specific (short range) solute/solvent interactions, that is, those occurring in the first solvation sphere. Thus, the conclusions drawn based on the calculations where such interactions occur should be interpreted with care. Although PCM operates better in aprotic solvents it has also been used to predict the solvation effect in protic solvents [15, 39].

Keeping in mind the limitations of the implicit solvent models PCM approach was applied to both minimum energy structures and saddle point configurations. In our previous papers [23] we showed that almost the entire solvent effect is achieved after single point PCM calculations, and no significant energy changes were observed during the optimization in water. Moreover, we showed that the TS geometry changes were not so profound as those experienced with the classical Menshutkin reaction [17, 40]. Although previously we studied the solvent effect in three solvents this time we decided to carry out full optimization only in two solvents, that is chloroform and water. We resigned from doing the calculation in ethanol because energy changes in ethanol and water were roughly the same. 


\section{$\begin{array}{lllll}\mathbf{R} & \text { RC } & \text { TS } & \text { IP } & \text { P }\end{array}$}
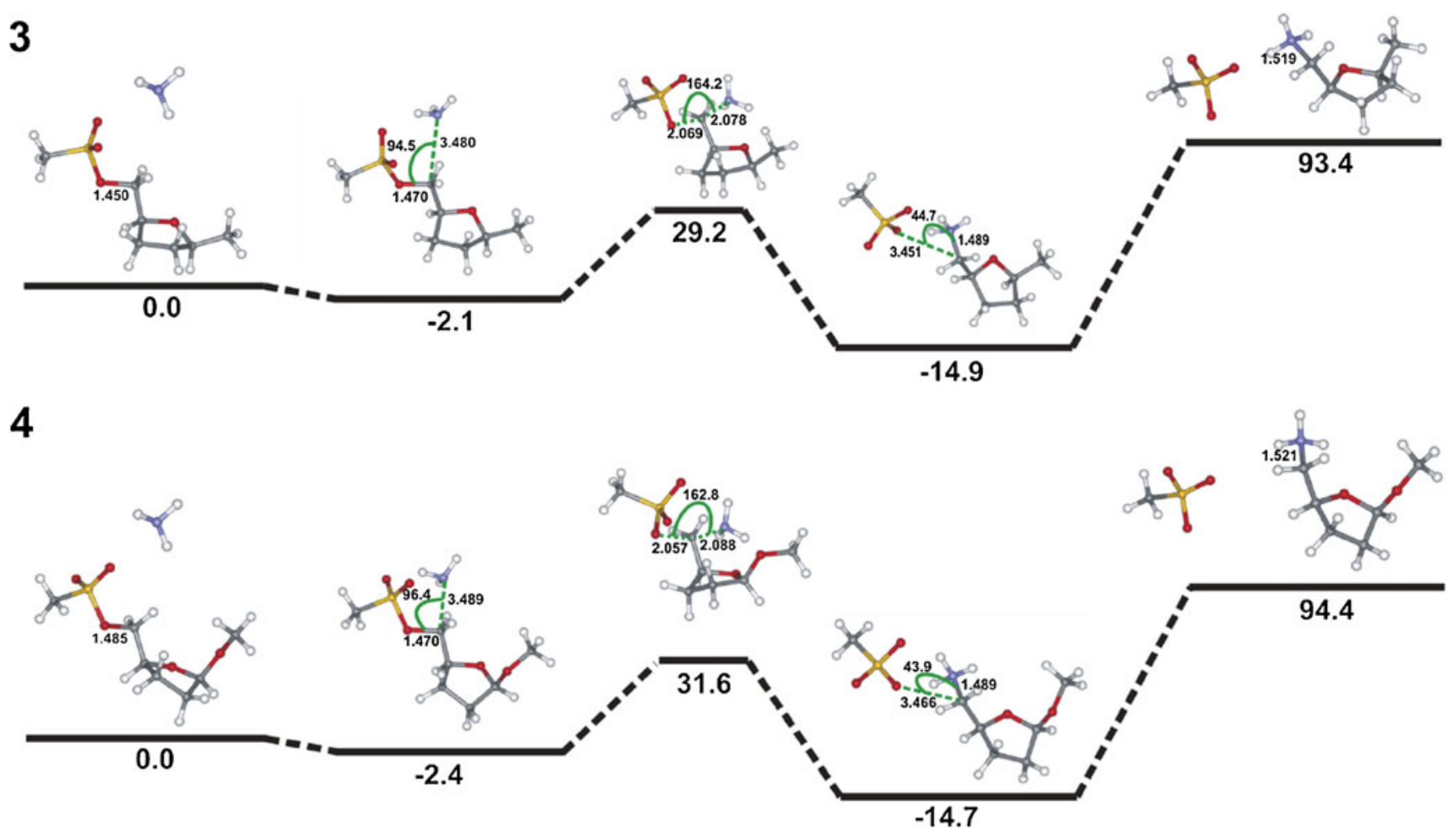

Fig. 6 Geometries of the stationary points and $\Delta E\left(\mathrm{kcal} \mathrm{mol}^{-1}\right)$ computed at the B3LYP/6-31+G** level for reactions 3 and 4 in the gas phase. Selected distances in $\AA$, and valence angles in degrees

The results of calculations in chloroform and in water are listed in Table 4 whereas Fig. 9 illustrates the geometries of the transition states optimized in water.

Significant changes in the energy diagrams are observed along the reaction path in both solvents, as compared with the gas phase (Fig. 3), especially on the product side. In chloroform, a solvent of low polarity, the energy sum of the separated ions decreases dramatically, but the overall process is still endothermic, relative energy ranges from $23 \mathrm{kcal} \mathrm{mol}^{-1}$ (reactions 2 and $\mathbf{3}$ ) to almost $29 \mathrm{kcal} \mathrm{mol}^{-1}$ (reaction 1), with respect to individual reactants (Table 4). The Gibbs free energy also predicts the process to be slightly unfavorable $\left(\Delta G \approx 4 \mathrm{kcal} \mathrm{mol}^{-1}\right)$. In very polar solvent, in turn, the reactions are exothermic and favorable. The energies of the separated ions are less than those of the individual reactants by about $-2 \mathrm{kcal} \mathrm{mol}^{-1}$ (reaction 1) and about $5 \mathrm{kcal} \mathrm{mol}^{-1}$ for other reactions.

According to the $\Delta U_{0}$ values, complexation is slightly exothermic in chloroform (Table 4). On the other hand, $\Delta G \mathrm{~s}$ indicate that this step of the reaction is strongly unfavorable, about $6 \mathrm{kcal} \mathrm{mol}^{-1}$, on average, must be supplied to form the reactant complex. Also, in water medium the reactant complex formation is unfavorable. It means that interactions between the constituents of the reactant complex are rather weak. The same conclusions were drawn previously [21-23].
Castejon et al. [17] studied the relationship between the stability of the reactant complexes (and ion pairs as well) and solvent polarity for the Menshutkin reaction. They noticed that neither the reactant complex nor the ion pair were energy minima in very polar solvents, like dimethyl sulfoxide. However, in our case they appeared to be real energy minima in water, although certain geometry differences were observed. The geometries of reactant complexes and ion pairs are roughly the same within the mesylate derivatives in the gas phase and in water. However, the reactant complexes differ in the relative positions of their constituents. The $\mathrm{C}^{\cdots \cdots} \mathrm{N}$ distance is $3.488 \AA$ on average in the gas phase, whereas in water it is much longer, about $3.7 \AA$. The reactant complexes and ion pairs formed in the reactions under discussion owe their stability to the hydrogen bonds formed between $\mathrm{H}$ and $\mathrm{O}$ atoms from the nucleophile and mesylate moiety respectively.

Both $\Delta U_{0}$ and $\Delta G$ showed that ion pair formation was an exoenergetic process in solvents with respect to the reactant complex, as in a vacuum. In reaction $\mathbf{1}$ taking place in chloroform the decrease in energy is $-12.9 \mathrm{kcal} \mathrm{mol}^{-1}(\Delta G)$, whereas in water the conversion of the reactant complex into the ion pair is more exoenergetic $\left(-16.8 \mathrm{kcal} \mathrm{mol}^{-1}\right)$ than in chloroform. The free energy changes accompanying ion pair formation in the other three reactions are roughly the same 
Table 3 Activation energies calculated for the conversion of reactant complexes 1a, 2a, 3a and 4a in the gas phase. All energy values in $\mathrm{kcal} \mathrm{mol}^{-1}$

\begin{tabular}{|c|c|c|c|c|}
\hline & \multicolumn{2}{|c|}{ B3LYP/6-31+G** } & \multicolumn{2}{|c|}{ MPW1K/6-31+G** } \\
\hline & $\Delta E^{\ddagger}$ & $\Delta G^{\star}$ & $\Delta E^{\ddagger}$ & $\Delta G^{\ddagger}$ \\
\hline Reaction 1 & 32.22 & 33.13 & 34.78 & 35.62 \\
\hline Reaction 2 & 30.98 & 32.79 & 33.88 & 35.61 \\
\hline Reaction 3 & 31.26 & 32.66 & 34.10 & 36.03 \\
\hline Reaction 4 & 33.18 & 35.50 & 36.17 & 38.73 \\
\hline
\end{tabular}

(about $-14 \mathrm{kcal} \mathrm{mol}^{-1}$ and $17 \mathrm{kcal} \mathrm{mol}^{-1}$ in chloroform and water, respectively), as for the reaction $\mathbf{1}$.

Optimization of transition states in chloroform leads to rather insignificant geometry changes. These changes are the greatest for the reaction 1 , where the $\mathrm{C} \cdots \mathrm{O}$ distance decreases from $2.060 \AA$ in the gas phase to $1.967 \AA$ in chloroform, and the $\mathrm{C}^{\cdots} \mathrm{N}$ distance increases from $1.932 \AA$ to $2.040 \AA$ (Table 4). This means that the transition state is shifted toward an earlier stage of the reaction. For the other three reactions the transition state geometry changes are even less.

In turn, more significant changes in transition state geometry, in relation to the gas phase, take place during optimization in water, especially for reactions 1 and 4 . In reaction 1 the $\mathrm{C} \cdots \mathrm{O}$ distance decreases to $1.909 \AA$ whereas the $\mathrm{C}^{\cdots} \mathrm{N}$ distance increases to $2.113 \AA$ with respect to the values found in the gas phase. Analogous geometry changes in transition state geometries occur for reactions $\mathbf{2}$ and $\mathbf{3}$, however, here the $\mathrm{C}^{\cdots} \mathrm{O} \mathrm{O}$ distance decreases by about $0.05 \AA$, whereas the $\mathrm{C}^{\cdots} \mathrm{N}$ distance increases by about $0.1 \AA$. The described geometrical changes are not as profound as in the classical Menshutkin reaction [17, 40]. Like in chloroform, these geometrical changes shifts transition states back to an earlier stage of the reaction.

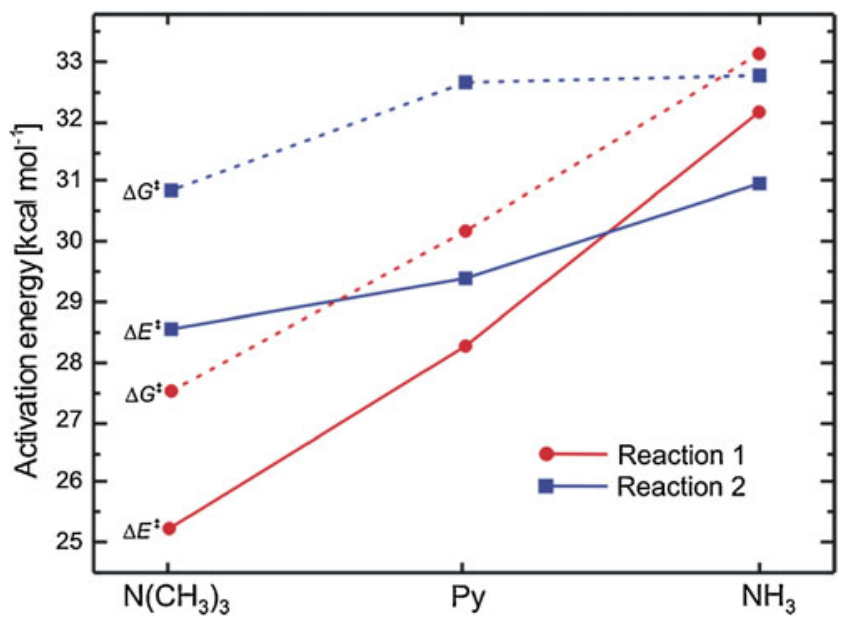

Fig. 7 Comparison of activation barriers for reactions 1 and 2 with different nucleophiles in the gas phase

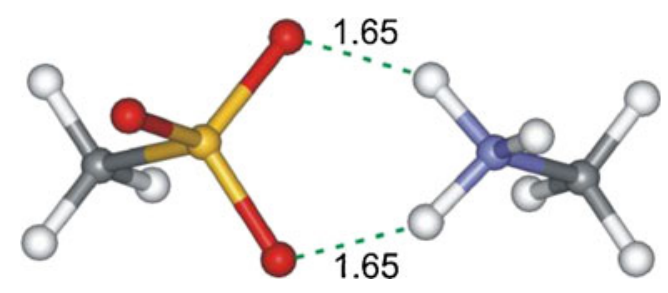

Fig. 8 Geometry of the ion pair in reaction 1

Apart from the geometry changes at the reaction center, there is an additional variation of the transition states in reactions $\mathbf{2}-\mathbf{4}$, particularly in water. In reaction 2 the $\mathrm{O}-\mathrm{C} 1-\mathrm{C} 2-\mathrm{C} 3$ torsion angle (A, Table 4$)$ increases from $-13.0^{\circ}$ in the gas phase to $53.8^{\circ}$ in water. The value is similar for reaction $3\left(43.2^{\circ}\right)$, whereas for conversion 4 it is $6.0^{\circ}$. This indicates that in two TSs (reactions $\mathbf{2}$ and $\mathbf{3}$ ) the leaving group is shifted above the THF ring. Rotation about the $\mathrm{C} 1-\mathrm{C} 2$ bond induces the ring conformation switch $\left({ }^{4} T_{3} \rightarrow E_{5}\right)$ in reaction 3 . In reactions $\mathbf{2}$ and $\mathbf{4}$ the THF ring conformation changes are not significant $\left({ }^{3} T_{4} \rightarrow E_{4}\right)$.

It is well recognize that the transfer from the gas phase to solvent leads to a significant energy barrier drop. Indeed, the B3LYP level barriers calculated in both solvents are much lower than those calculated for the gas phase. In the case of the reaction $\mathbf{1}$ occurring in chloroform, calculated barrier is lower by about $8 \mathrm{kcal} \mathrm{mol}^{-1}$ whereas in water it is ca $13 \mathrm{kcal} \mathrm{mol}^{-1}$ less. For the other three reactions the differences between barriers in the gas phase and in solvents are significantly lower. For the reaction $\mathbf{4}$ barriers are lower by about $5 \mathrm{kcal} \mathrm{mol}^{-1}$ and $8 \mathrm{kcal} \mathrm{mol}^{-1}$ in chloroform and water, respectively.

A different barriers height order is found in the gas phase and in solvents. In the gas phase the lowest barrier was found for the reaction 2 . In turn, for the reaction 1 taking place in chloroform the barrier is by about $3 \mathrm{kcal} \mathrm{mol}^{-1}$ lower than for the reaction $\mathbf{2}$. The difference between barrier height are even greater in water. This may suggest that hydrogen bond stabilizing TS in the gas phase is weaker in solvents.

Like in the gas phase also in solvents the barrier height depends on the type of the substituent at C5. The presence of a spatial group attached to this carbon atom slightly increases the barrier, although the differences are rather small in chloroform. It is difficult to judge which reaction, $\mathbf{2}$ or $\mathbf{3}$ should be faster, based on the free energy barriers calculated in water.

The transfer from the gas phase to the solvent leads to a significant energy drop in the final step of these reactions. While separating the ion pair constituents requires about $100 \mathrm{kcal} \mathrm{mol}^{-1}(\Delta G)$ in a vacuum, in chloroform over $30 \mathrm{kcal} \mathrm{mol}^{-1}$ need to be supplied to accomplish this step of the reaction. In water, in turn, only about $5 \mathrm{kcal} \mathrm{mol}^{-1}$ are required. 


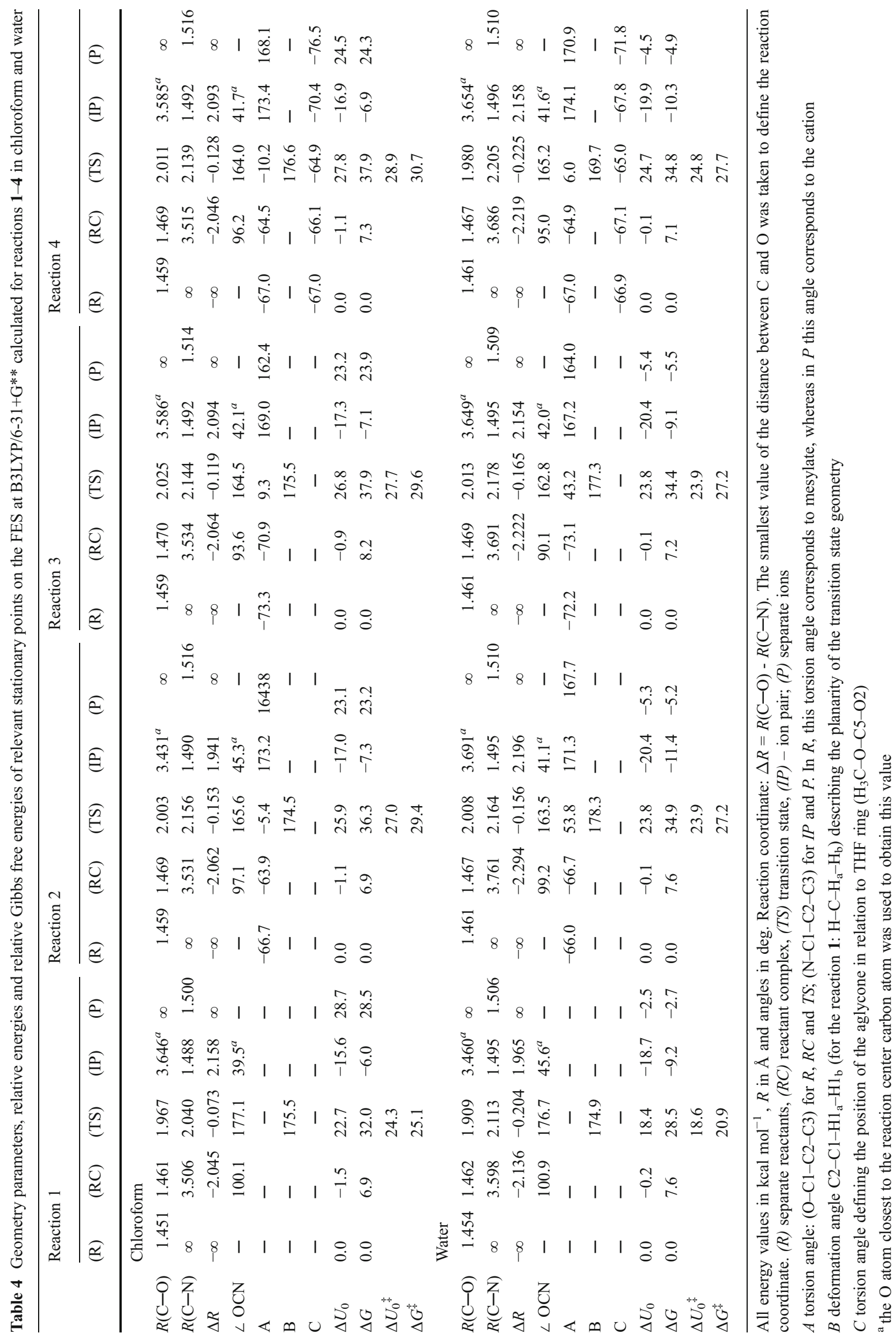


Fig. 9 Geometries of the transition states optimized at the B3LYP/6-31+G** level in water. Selected distances in $\AA$, and valence angles in degrees
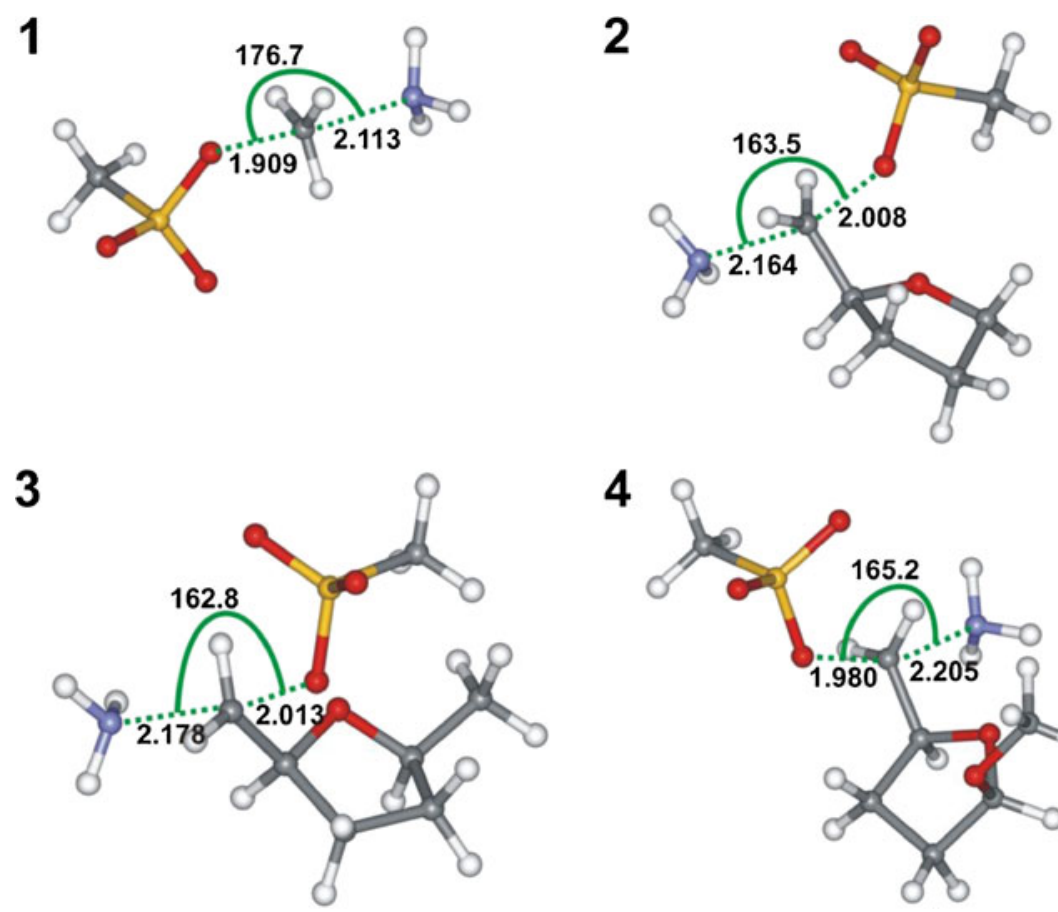

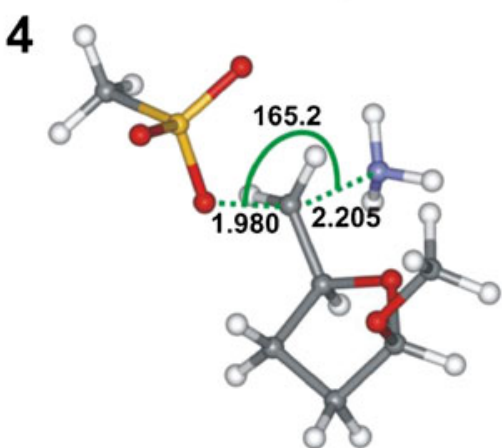

\section{Conclusions}

In this work we continued our DFT study into ammonium salt formation in a Menshutkin-like reaction between ammonia and four mesylate derivatives: methyl mesylate (1a), (S)-1,4-andydro-2,3-dideoxy-5-O-mesylpentitol (2a), (2S,5S)-2,5-andydro-1,3,4-trideoxy-6-O-mesylhexitol (3a) and methyl 2,3-dideoxy-5- $O$-mesyl- $\beta$-D-pentofuranoside (4a). The reactions were investigated using the B3LYP functional with the $6-31+\mathrm{G}^{* *}$ basis set in the gas phase and in solvents. Additionally, MPW1K/6-31+G** level calculations were carried out to estimate activation barrier heights. Apart from that, the reactions were studied in two solvents (chloroform and water) using the PCM model.

The energy diagrams presented in Fig. 3 exhibit two minima corresponding to the reactant complex and the ion pair in the gas phase. Clearly, ion pairs are more stable than the respective reactant complexes, but this is not a golden rule. For example, in the reaction between methyl mesylate and pyridine the reactant complex is more stable. The two strong hydrogen bonds formed between the mesylate anion and the ammonium cation are responsible for the extraordinary stability of the ion pair with respect to the individual reactants. The ion pair stability is even greater in solvents. This unusual stabilization of ion pairs causes the final step of the reaction to be endergonic in solvents.

Energy and Gibbs free energy values indicate that the overall process is highly unfavorable in the gas phase. In chloroform it is still unfavorable, but in more polar solvents the sum of the energies of the individual ions is less than that of the separate reactants.
According to B3LYP and MPW1K functionals, the energy barrier is the lowest for reaction $\mathbf{2}$ and not reaction $\mathbf{1}$, in contrast to the reactions with trimethylamine or pyridine. However, reaction 1 should be the fastest one in solvents used in the calculations. In turn, reaction $\mathbf{4}$ seems to be the slowest, both in the gas phase and in chloroform. In water, however, the difference between calculated barriers are insignificantly small thus do not indicate univocally the reaction 4 to be the slowest one. It should be emphasized once again at this place that reaction field models do not describe hydrogen bonding interaction which could affect the energetics of reactions studied thus results of the calculations in water should be taken with care. Possibly the solution for this problem would be achieved based on the calculation of the model with discrete water molecule.

We have also discussed the conformational behavior of the THF ring along the reaction pathway, noting that in reactions 2 and $\mathbf{4}$ the THF ring adopts a conformation from the narrow region of the northern half of the pseudorotational circle. In turn, the THF ring is solely in conformations located in the southern half in reaction 3. The THF ring conformation switch $\left({ }^{4} T_{3} \rightarrow E_{5}\right)$ was observed for the reaction 3 transition state geometry during the optimization in water, which is the result of rotation about the $\mathrm{C} 1-\mathrm{C} 2$ bond.

Acknowledgments This work was supported by DS/530-8451-D193-13. All DFT calculations were carried out using the resources of the Informatics Centre of the Metropolitan Academic Network in Gdańsk (CI TASK). 
Open Access This article is distributed under the terms of the Creative Commons Attribution License which permits any use, distribution, and reproduction in any medium, provided the original author(s) and the source are credited.

\section{References}

1. Menschutkin N (1890) Z Physik Chem 5:589-601

2. Fischer E, Raske K (1910) Chem Ber 43:1750-1753

3. Pellowska-Januszek L, Dmochowska B, Skorupa E, Chojnacki J, Wojnowski W, Wiśniewski A (2004) Carbohydr Res 339:1537-1544

4. Skorupa E, Dmochowska B, Pellowska-Januszek L, Wojnowski W, Chojnacki J, Wiśniewski A (2004) Carbohydr Res 339:2355-2362

5. Dmochowska B, Skorupa E, Pellowska-Januszek L, Czarkowska M, Sikorski A, Wiśniewski A (2006) Carbohydr Res 341:1916-1921

6. Dmochowska B, Skorupa E, Świtecka P, Sikorski A, Łacka I, Milewski S, Wiśniewski AJ (2009) Carbohydr Chem 28:222-233

7. Mantell SJ, Ford PS, Watkin DJ, Fleet GWJ, Brown D (1993) Tetrahedron 49:3343-3358

8. Viers JW, Schug JC, Stovall MD, Seeman JI (1984) J Comput Chem 5:598-605

9. Solà M, Lledós A, Duran M, Bertrán J, Abboud J-LM (1991) J Am Chem Soc 113:2873-2879

10. Gao J, Xia X (1993) J Am Chem Soc 115:9667-9675

11. Maran U, Pakkanen TA, Karelson M (1994) J Chem Soc Perkin Trans 2:2445-2452

12. Shaik S, Ioffe A, Reddy AC, Pross A (1994) J Am Chem Soc $116: 262-273$

13. Fradera X, Amat L, Torrent AM, Mestres J, Constans P, Besalú E, Martí J, Simon S, Lobato M, Oliva JM, Luis JM, Andrés M, Solà M, Carbó R, Duran M (1996) J Mol Struct (THEOCHEM) 371:171-183

14. Truong TN, Truong T-TT, Stefanovich EV (1997) J Chem Phys 107:1881-1889

15. Amovilli C, Mennucci B, Floris FM (1998) J Phys Chem B 102:3023-3028

16. Webb SP, Gordon MS (1999) J Phys Chem A 103:1265-1273

17. Castejon H, Wiberg KB (1999) J Am Chem Soc 121:2139-2146

18. Poater J, Solà M, Duran M, Fradera X (2001) J Phys Chem A 105:6249-6257

19. Fábián A, Ruff F, Farkas Ö (2008) J Phys Org Chem 21:988-996

20. Acevedo O, Jorgensen WL (2010) J Phys Chem B 114:8425-8430

21. Nowacki A, Dmochowska B, Jączkowska E, Sikora K, Wiśniewski A (2011) Comput Theor Chem 973:53-61

22. Nowacki A, Dmochowska B, Sikora K, Madaj J, Wiśniewski A (2012) Comput Theor Chem 986:85-92
23. Nowacki A, Sikora K, Dmochowska B, Wiśniewski A (2012) Comput Theor Chem 1000:33-41

24. Wu ESC, Griffith RC, Loch JT III, Kover A, Murray RJ, Mullen GB, Blosser JC, Machulskis AC, McCreedy SA (1995) J Med Chem 38:1558-1570

25. Schaftenaar G, Noordik JH (2000) J Comput Aided Mol Des $14: 123-134$

26. Becke AD (1993) J Chem Phys 98:5648-5652

27. Lee C, Yang W, Parr RG (1988) Phys Rev B 37:785-789

28. Hehre WJ, Ditchfield R, Pople JA (1972) J Chem Phys 56:22572261

29. Clark T, Chandrasekhar J, Spitznagel GW, von Ragué Schleyer P (1983) J Comp Chem 4:294-301

30. Lynch BJ, Fast PL, Harris M, Truhlar DG (2000) J Phys Chem A 104:4811-4815

31. Tomasi J, Persico M (1994) Chem Rev 94:2027-2094

32. Frisch MJ, Trucks GW, Schlegel HB, Scuseria GE, Robb MA, Cheeseman JR, Montgomery JA Jr, Vreven T, Kudin KN, Burant JC, Millam JM, Iyengar SS, Tomasi J, Barone V, Mennucci B, Cossi M, Scalmani G, Rega N, Petersson GA, Nakatsuji H, Hada M, Ehara M, Toyota K, Fukuda R, Hasegawa J, Ishida M, Nakajima T, Honda Y, Kitao O, Nakai H, Klene M, Li X, Knox JE, Hratchian HP, Cross JB, Bakken V, Adamo C, Jaramillo J, Gomperts R, Stratmann RE, Yazyev O, Austin AJ, Cammi R, Pomelli C, Ochterski JW, Ayala PY, Morokuma K, Voth GA, Salvador P, Dannenberg JJ, Zakrzewski VG, Dapprich S, Daniels AD, Strain MC, Farkas O, Malick DK, Rabuck AD, Raghavachari K, Foresman JB, Ortiz JV, Cui Q, Baboul AG, Clifford S, Cioslowski J, Stefanov BB, Liu G, Liashenko A, Piskorz P, Komaromi I, Martin RL, Fox DJ, Keith T, Al-Laham MA, Peng CY, Nanayakkara A, Challacombe M, Gill PMW, Johnson B, Chen W, Wong MW, Gonzalez C, Pople JA (2004) Gaussian 03, revision E.01. Gaussian, Inc, Wallingford

33. Kim Y, Mohring JR, Truhlar DG (2010) J Am Chem Soc 132:11071-11082

34. Andersson MP, Uvdal P (2005) J Phys Chem A 109:2937-2941

35. Altona C, Sundaralingam M (1972) J Am Chem Soc 94:82058212

36. Houseknecht JB, Altona C, Hadad CM, Lowary TL (2002) J Org Chem 67:4647-4651

37. Koch U, Popelier PLA (1995) J Phys Chem 99:9747-9754

38. Lias SG, Lieberman JF, Levin RD (1984) J Phys Chem Ref Data 13:695-808

39. Martínez AG, Vilar ET, Barcina JO, de la Moya Cerero S (2005) J Org Chem 70:10238-10246

40. Acevedo O, Jorgensen WL (2010) Acc Chem Res 43:142-151 